\title{
Synthesis and characterization of fully biobased copolyether polyols
}

Andere Basterretxea, Xabier Lopez de Pariza, Elena Gabirondo, Sara Marina, Jaime Martin, Agustin Etxeberria, David Mecerreyes, Haritz Sardon*

POLYMAT, University of the Basque Country UPV/EHU, Joxe Mari Korta Center, Avda. Tolosa 7, 20018 Donostia-San Sebastian, Spain

SUPPORTING INFORMATION

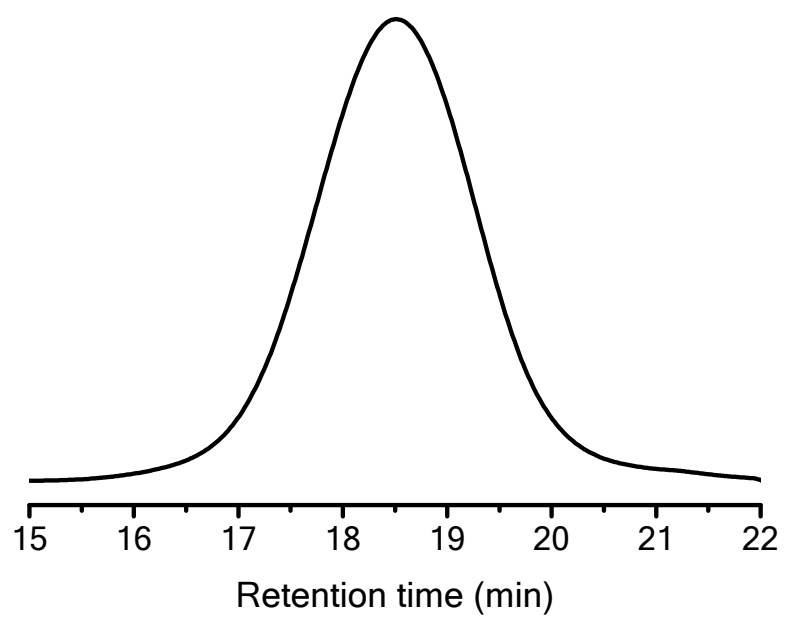

Figure S1.1. SEC trace of 100/0 (HDO/CHDM) 응 feed.

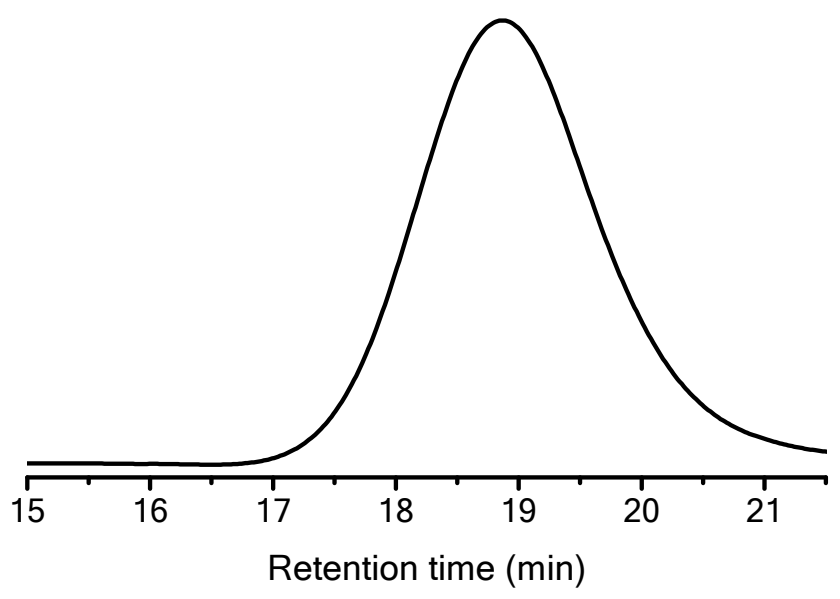

Figure s1.2. SEC trace of 90/10 (HDO/CHDM) in feed. 


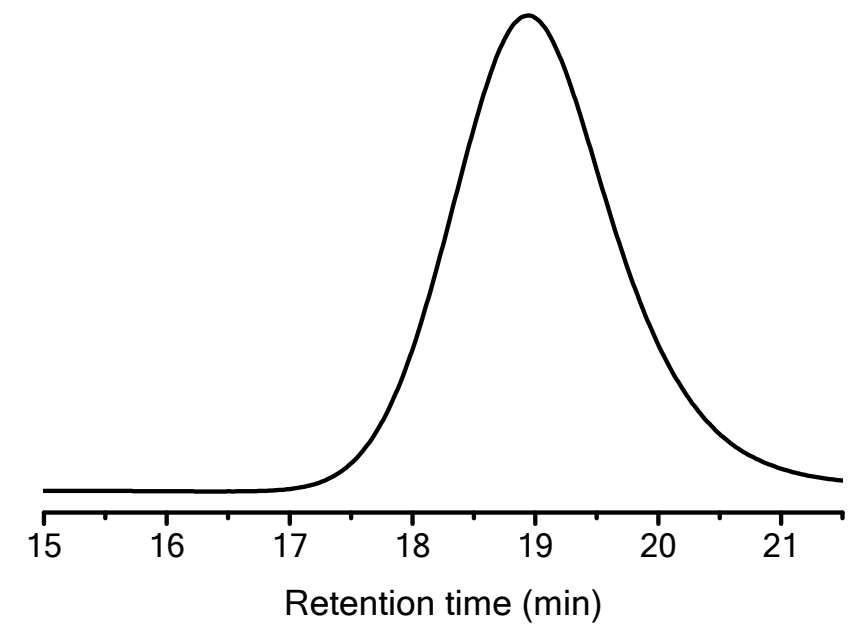

Figure S1.3. SEC trace of $80 / 20$ (HDO/CHDM) in feed.

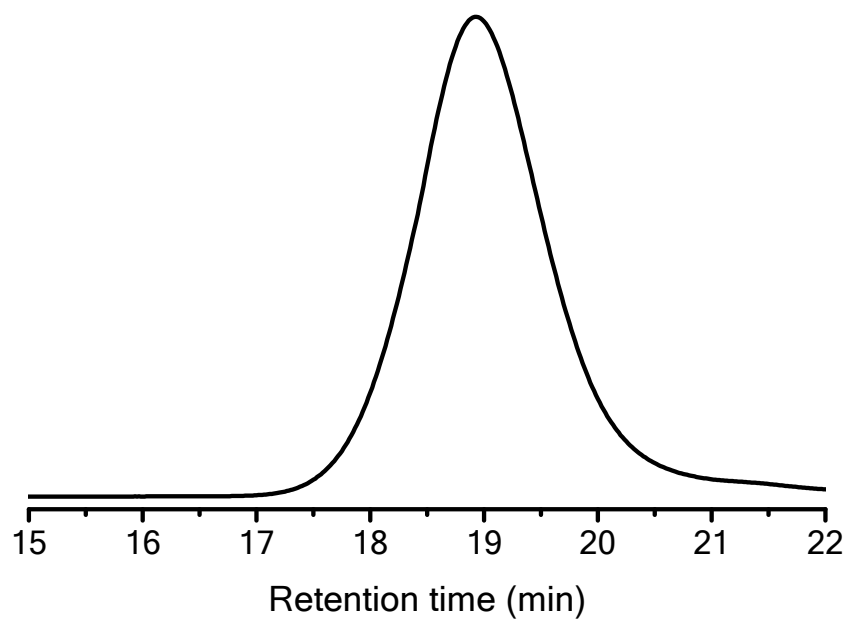

Figure s1.4. SEC trace of $70 / 30$ (HDO/CHDM) in feed. 


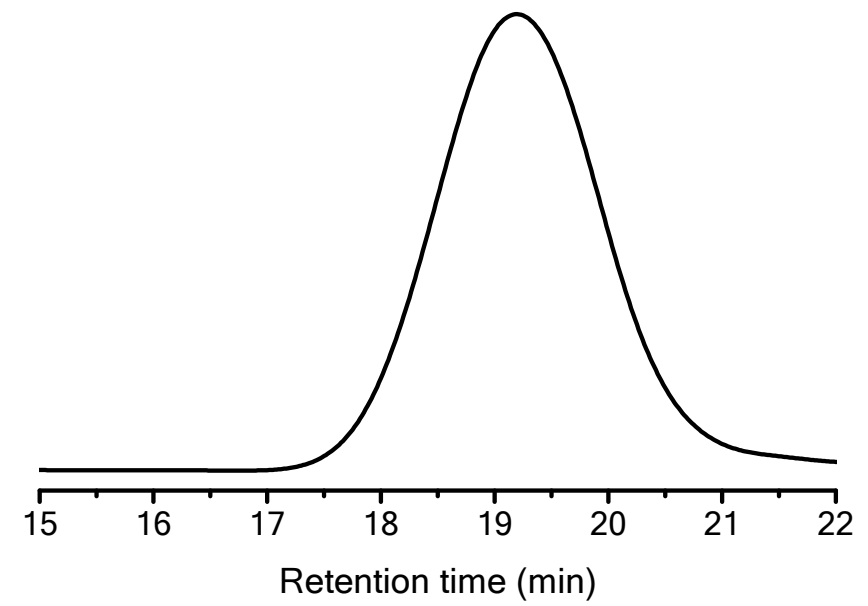

Figure s1.5. SEC trace of $50 / 50$ (HDO/CHDM) 을 feed.

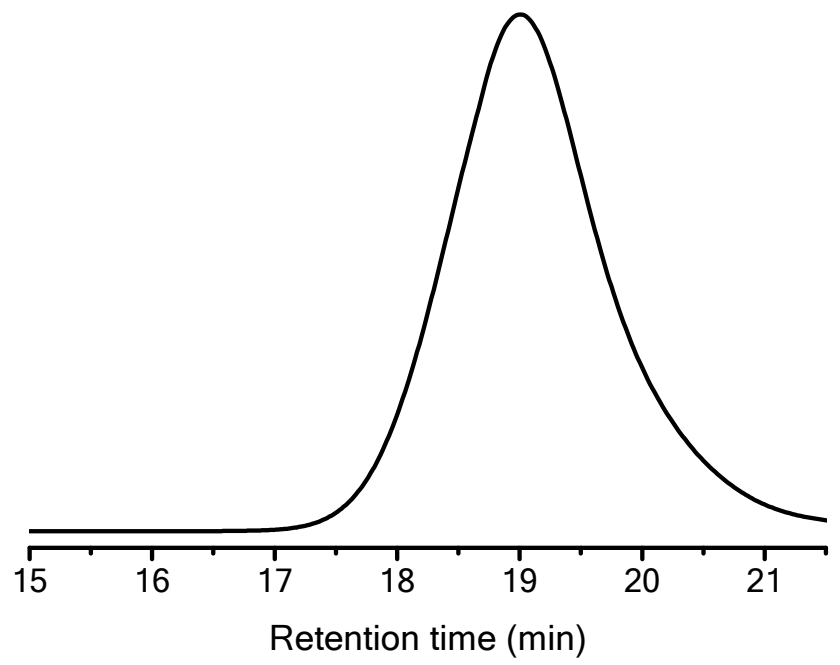

Figure S1.6. SEC trace of $30 / 70$ (HDO/CHDM) 응 in feed. 


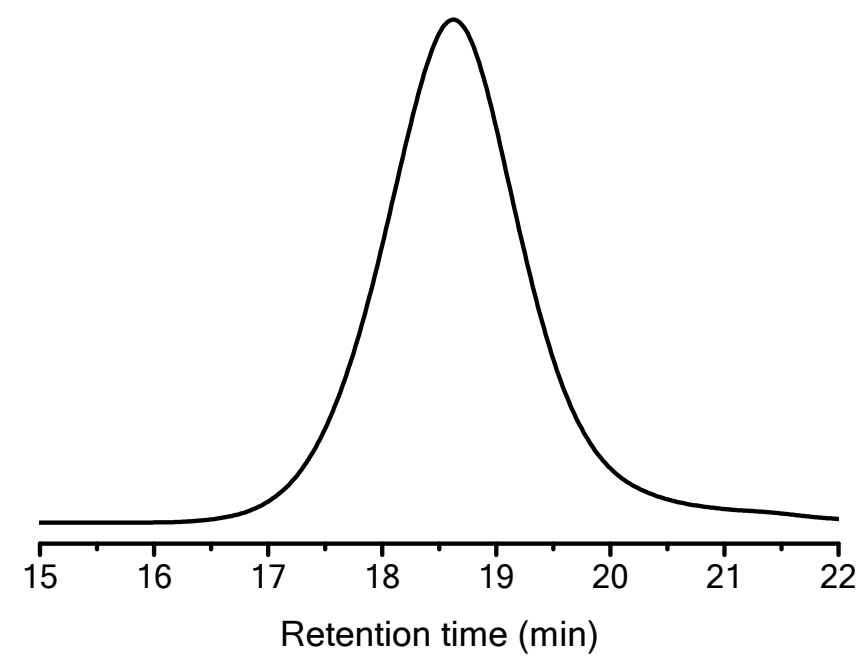

Figure s1.7. SEC trace of $20 / 80$ (HDO/CHDM) 을 feed.

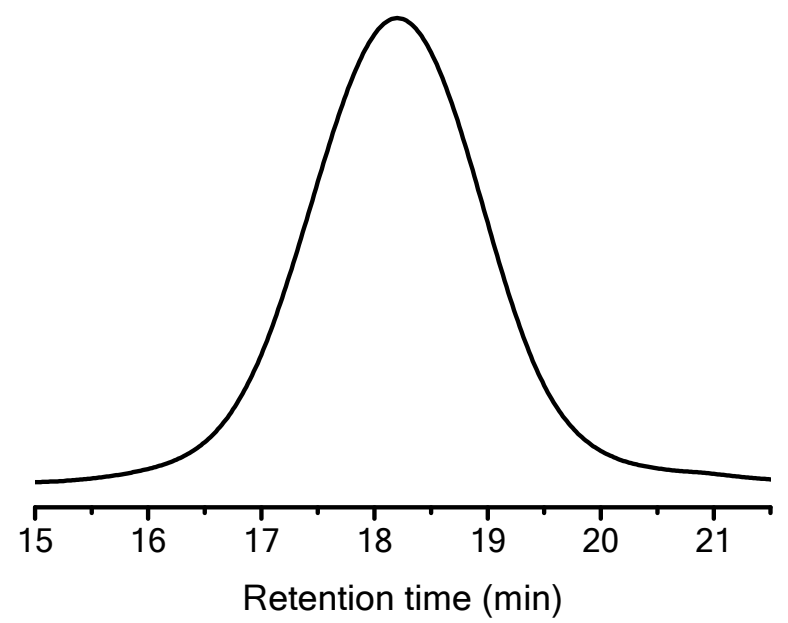

Figure s1.8. SEC trace of 0/100 (HDO/CHDM) in feed. 
Entry 1

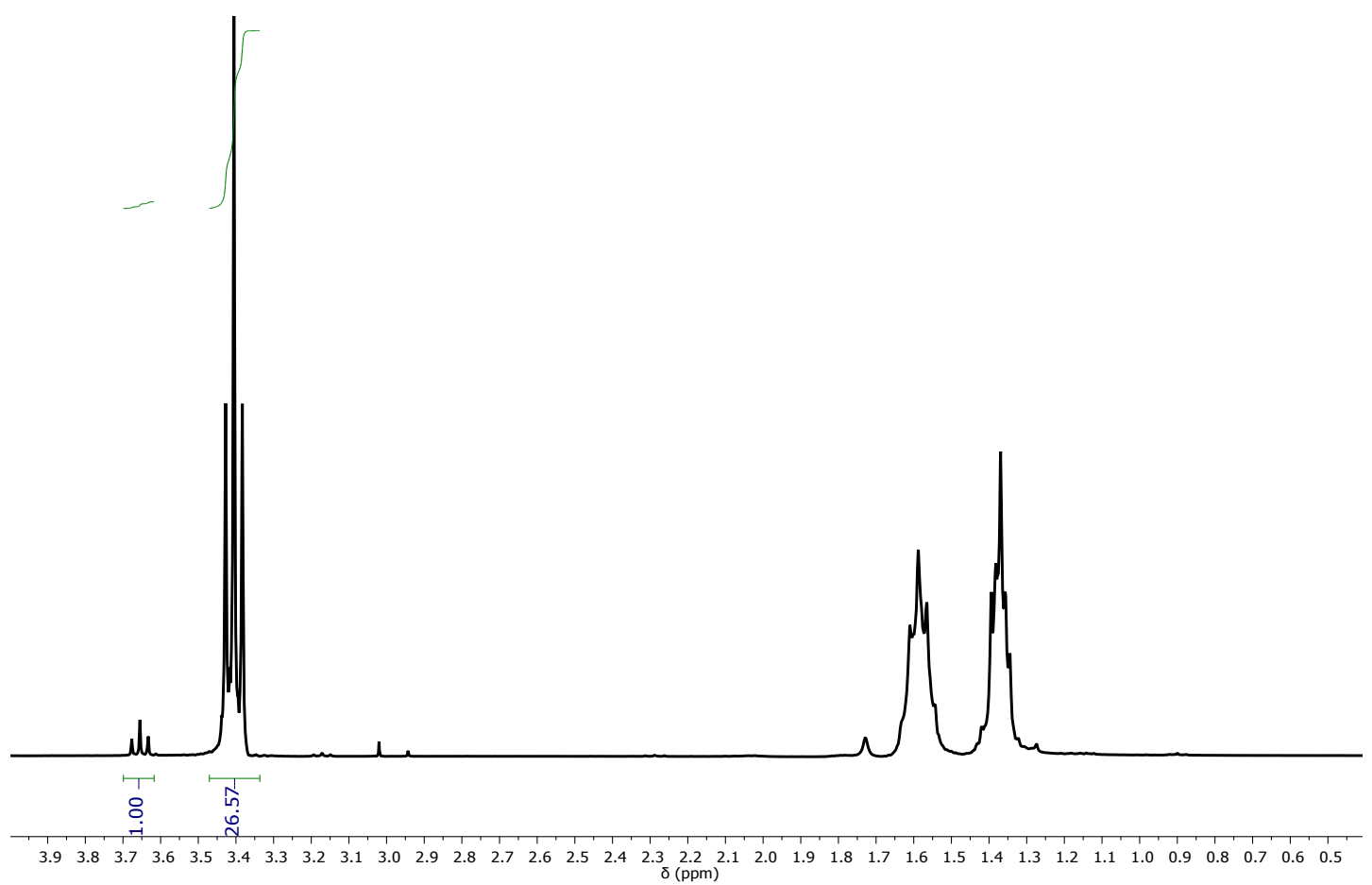

Figure S2.1. ${ }^{1} \mathrm{H}-\mathrm{NMR}$ of $100 / 0$ (HDO/CHDM) $\frac{\circ}{\circ}$ in feed.

Entry 2

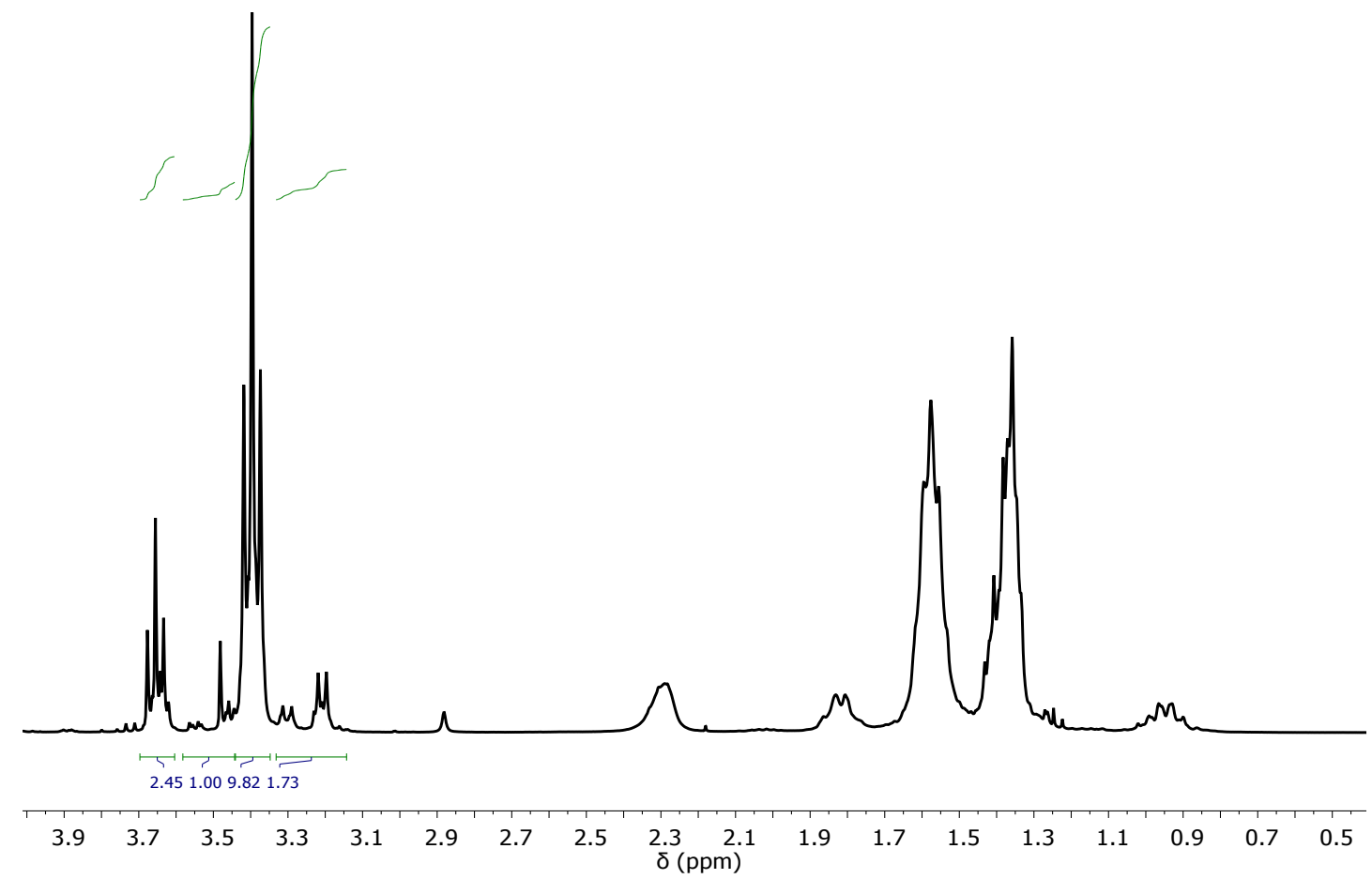

Figure S2.2. ${ }^{1} \mathrm{H}-\mathrm{NMR}$ of $90 / 10$ (HDO/CHDM) $\frac{\circ}{\circ}$ in feed. 
Entry 3

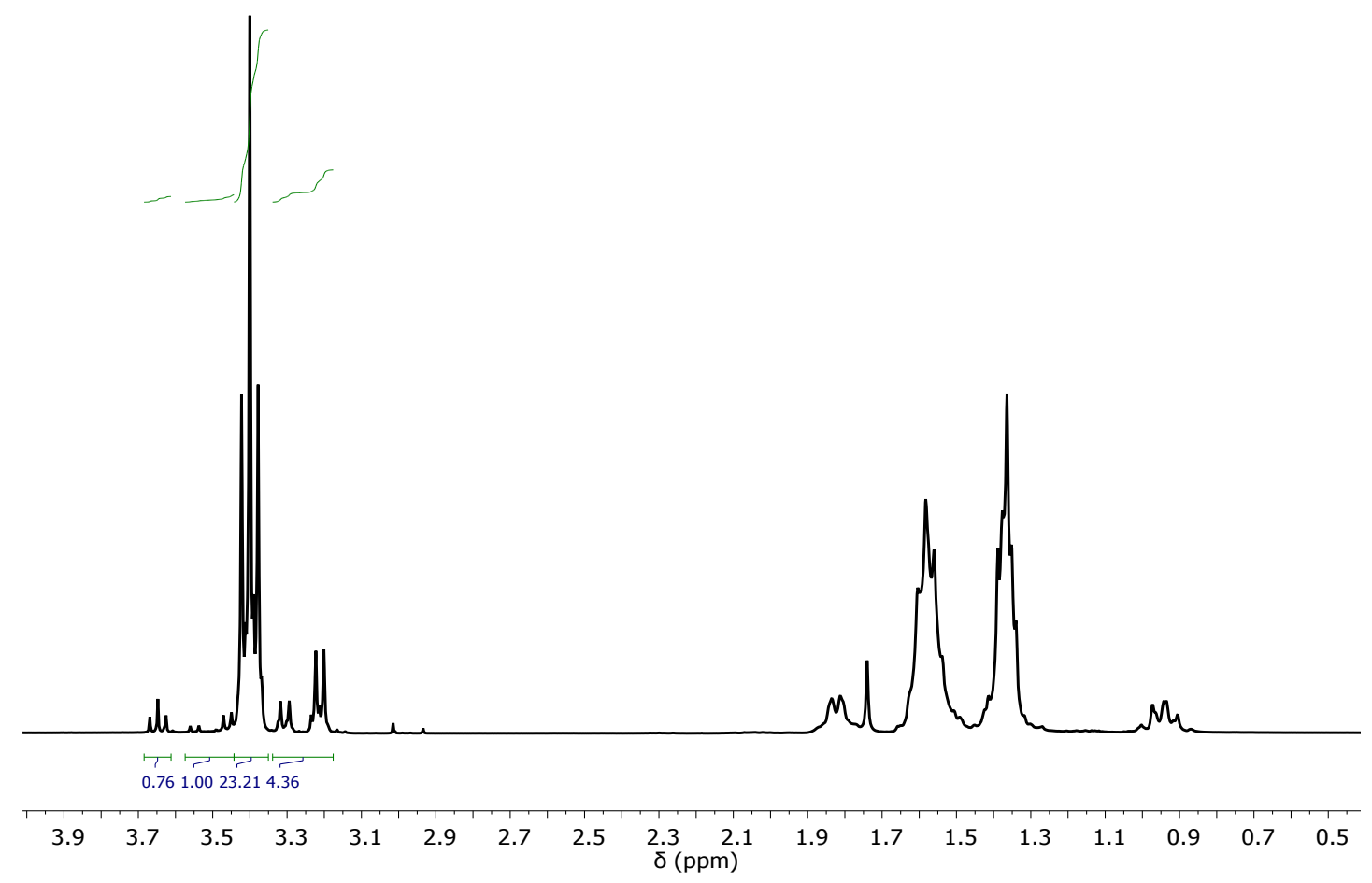

Figure S2.3. ${ }^{1} \mathrm{H}-\mathrm{NMR}$ of $80 / 20$ (HDO/CHDM) $\%$ in feed.

\section{Entry 4}

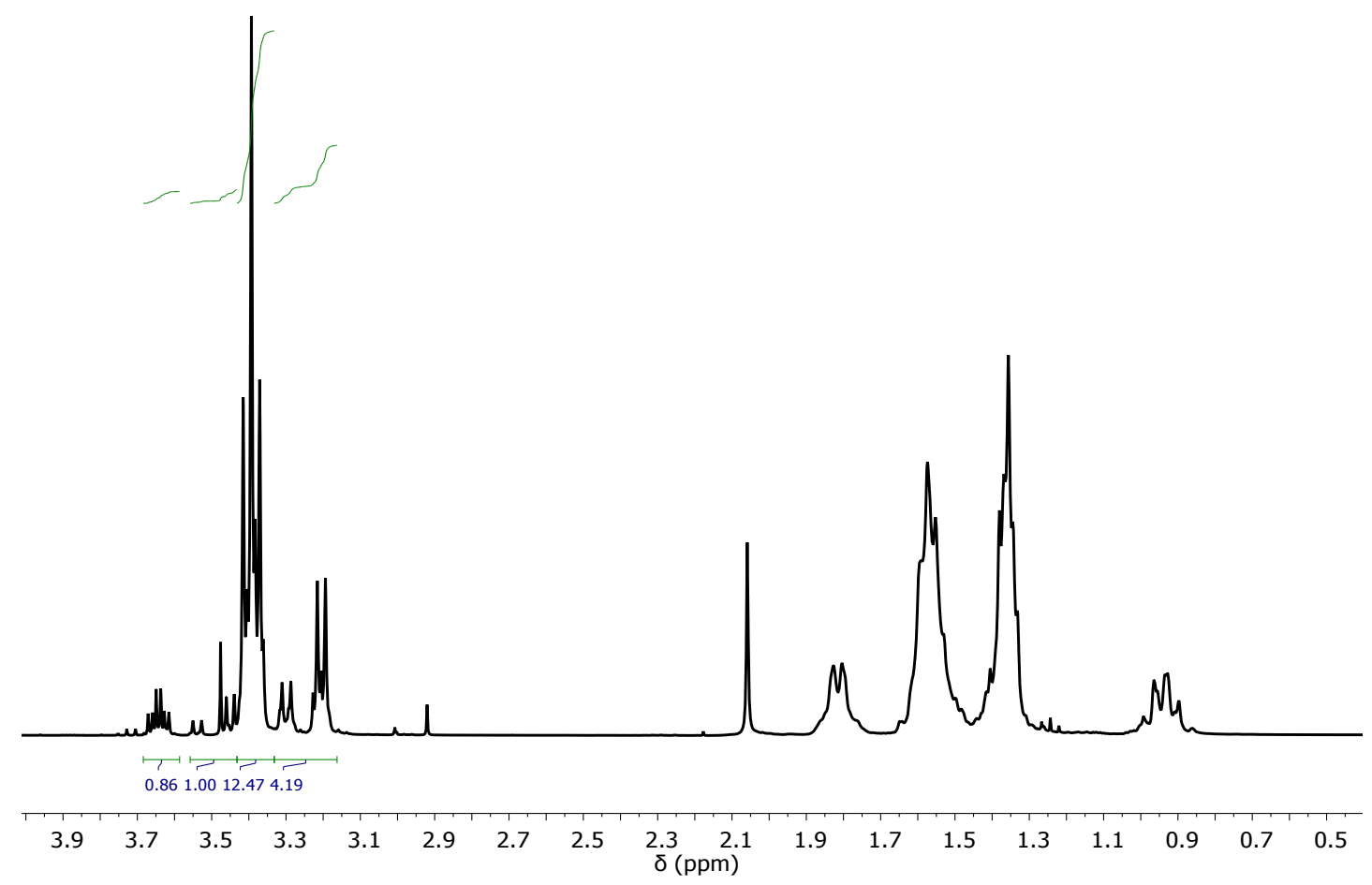

Figure S2.4. ${ }^{1} \mathrm{H}-\mathrm{NMR}$ of $70 / 30$ (HDO/CHDM) $\frac{\circ}{\circ}$ in feed. 
Entry 5

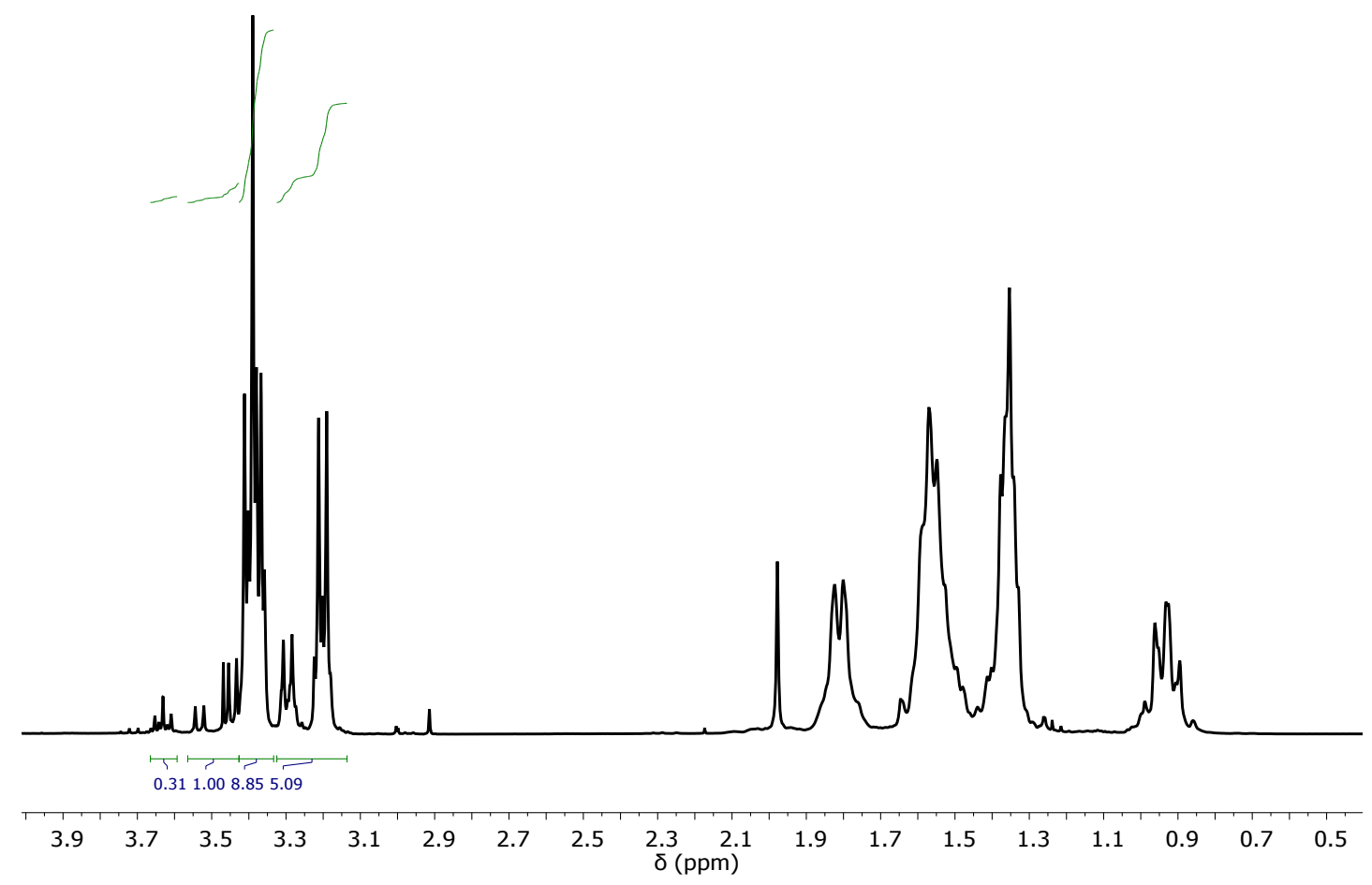

Figure S2.5. ${ }^{1} \mathrm{H}-\mathrm{NMR}$ of $50 / 50$ (HDO/CHDM) $\frac{\circ}{\circ}$ in feed.

\section{Entry 6}
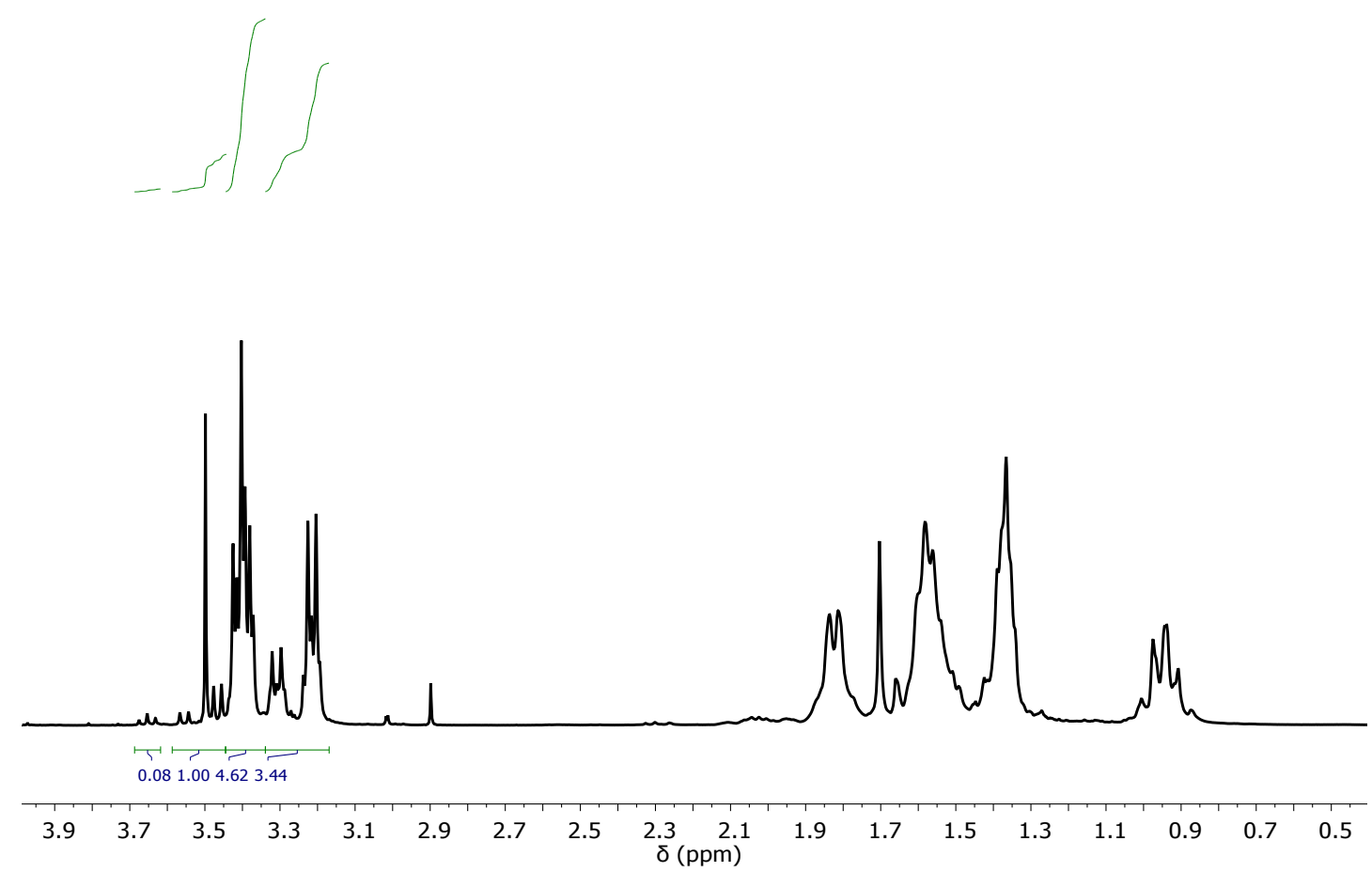

Figure S2.6. ${ }^{1} \mathrm{H}-\mathrm{NMR}$ of $30 / 70$ (HDO/CHDM) $\frac{\circ}{\circ}$ in feed. 


\section{Entry 7}

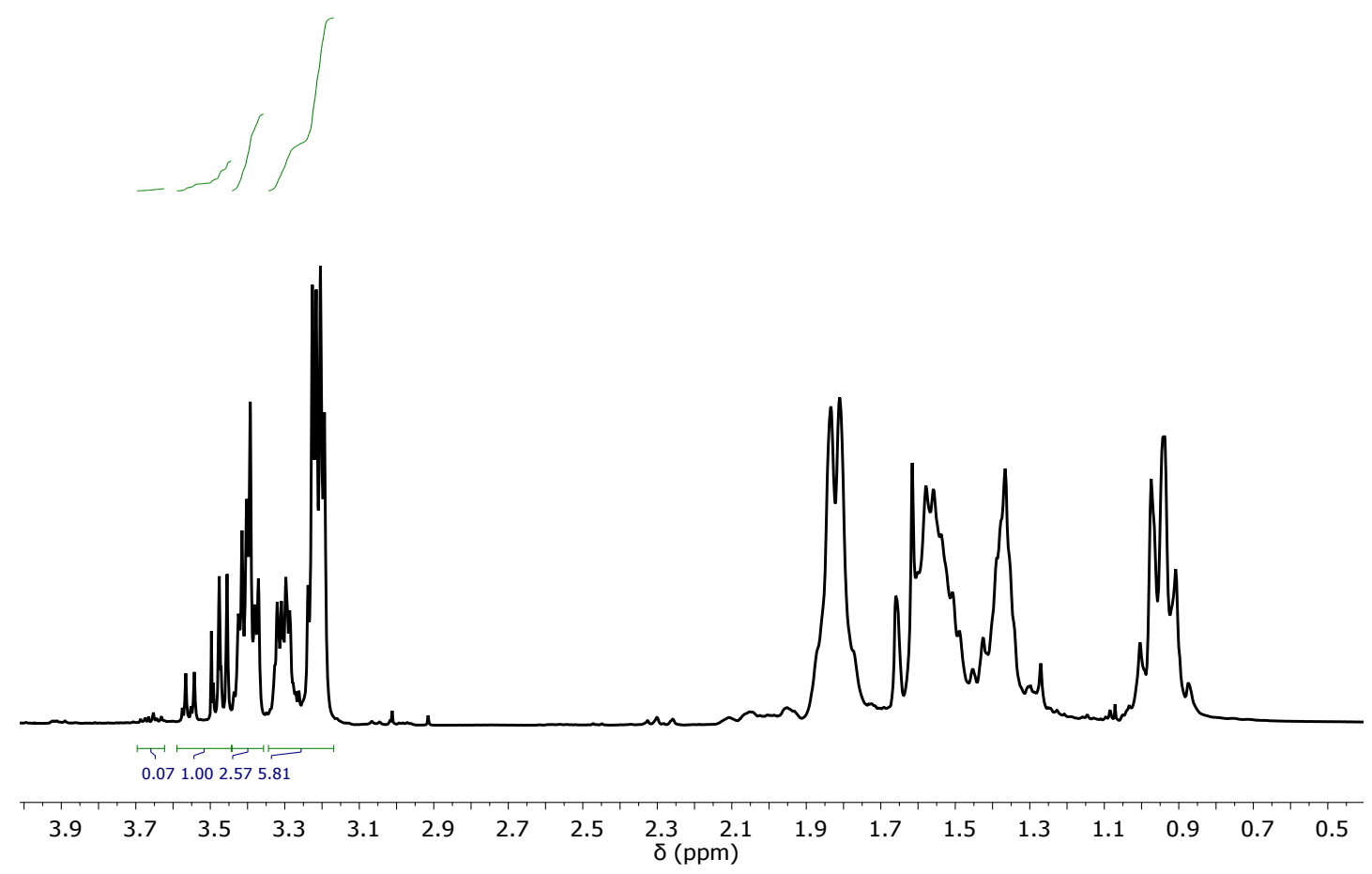

Figure S2.7. ${ }^{1} \mathrm{H}-\mathrm{NMR}$ of $20 / 80$ (HDO/CHDM) $\frac{\circ}{\circ}$ in feed.

\section{Entry 8}

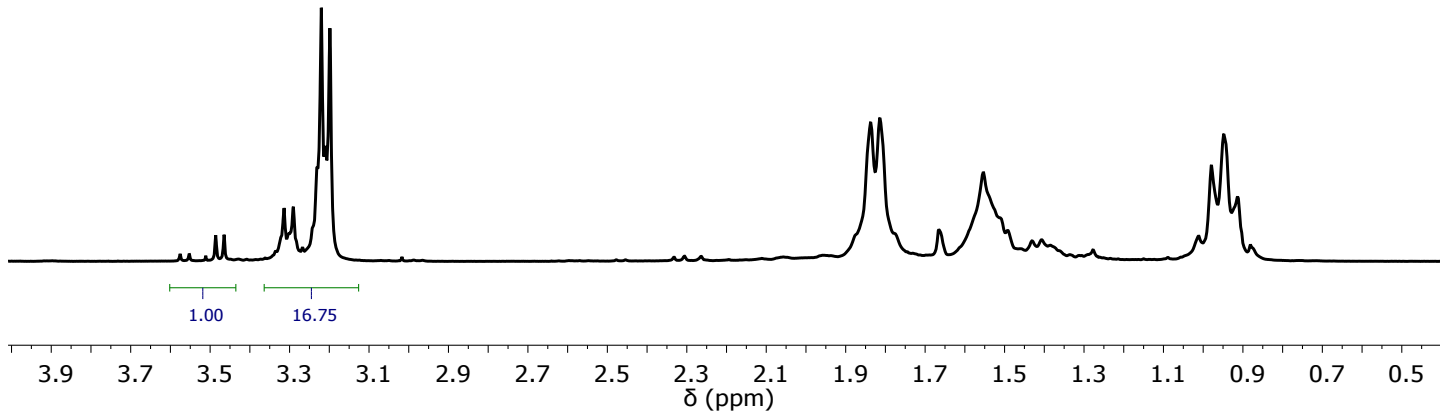

Figure S2.8. ${ }^{1} \mathrm{H}-\mathrm{NMR}$ of $0 / 100$ (HDO/CHDM) $\frac{\circ}{\circ}$ in feed. 


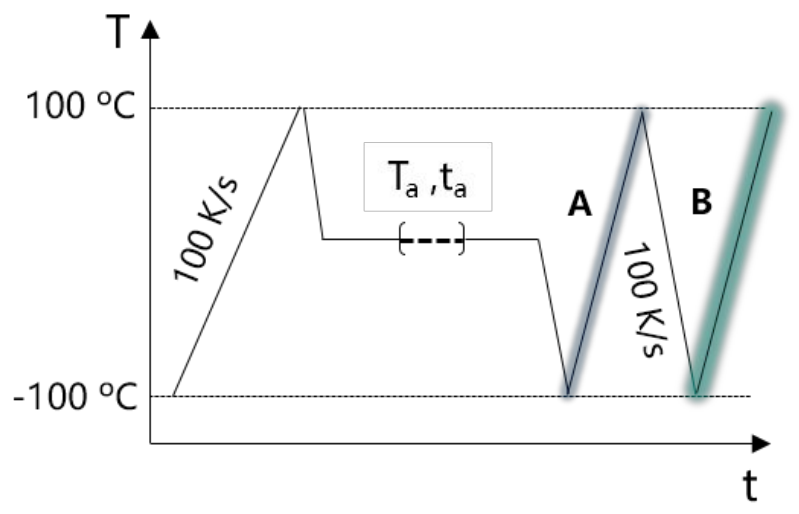

Figure s3. Thermal protocol applied in the isochronal relaxation experiments conducted to analyse the glass transition temperatures.

Shown in Figure S3Error! Reference source not found. is the analysis of the enthalpy recovery of the materials studied. The plots in Figure S3Error! Reference source not found.a-e are built by the superposition of the isothermally aged heating scans (blue curves corresponding to A-scan in Figure S2) against the heating scans of the unaged samples (green curves corresponding to B-scan in Figure S2)).

The heating scans of aged neat HDO (blue curves corresponding to A-scan in Figure S2) exhibited melting peaks at approximately $50^{\circ}$ and an endothermic overshoot due to the enthalpy relaxation process when it was aged in the temperature range from -95 to $-55^{\circ} \mathrm{C}$. Neat CHDO, conversely, did not exhibit any crystal melting, but the overshoot owing to the enthalpy relaxation was clearly visible for $\mathrm{T}_{\mathrm{a}} \mathrm{s}$ below $-60{ }^{\circ} \mathrm{C}$. In order to determine the $\mathrm{T}_{g}$ in quantitative means, the amount of relaxed enthalpy $(\Delta \mathrm{H})$ was measured at each $\mathrm{T}_{\mathrm{a}}$ by integration of the endothermic overshoots. The plot of the $\Delta \mathrm{H}$ VS $\mathrm{T}_{\mathrm{a}}$ clearly shows the $\mathrm{T}_{\mathrm{a}} \mathrm{S}$ at which $\Delta \mathrm{H}$ equals to zero, i.e. the $\mathrm{T}_{g}$ (Figure $\left.\mathrm{S} 3 \mathrm{f}-\mathrm{j}\right)$. As typically for random copolymers, the $\mathrm{T}_{g} \mathrm{~s}$ values of the HDO-CHDO blends lay in between those for neat components. 

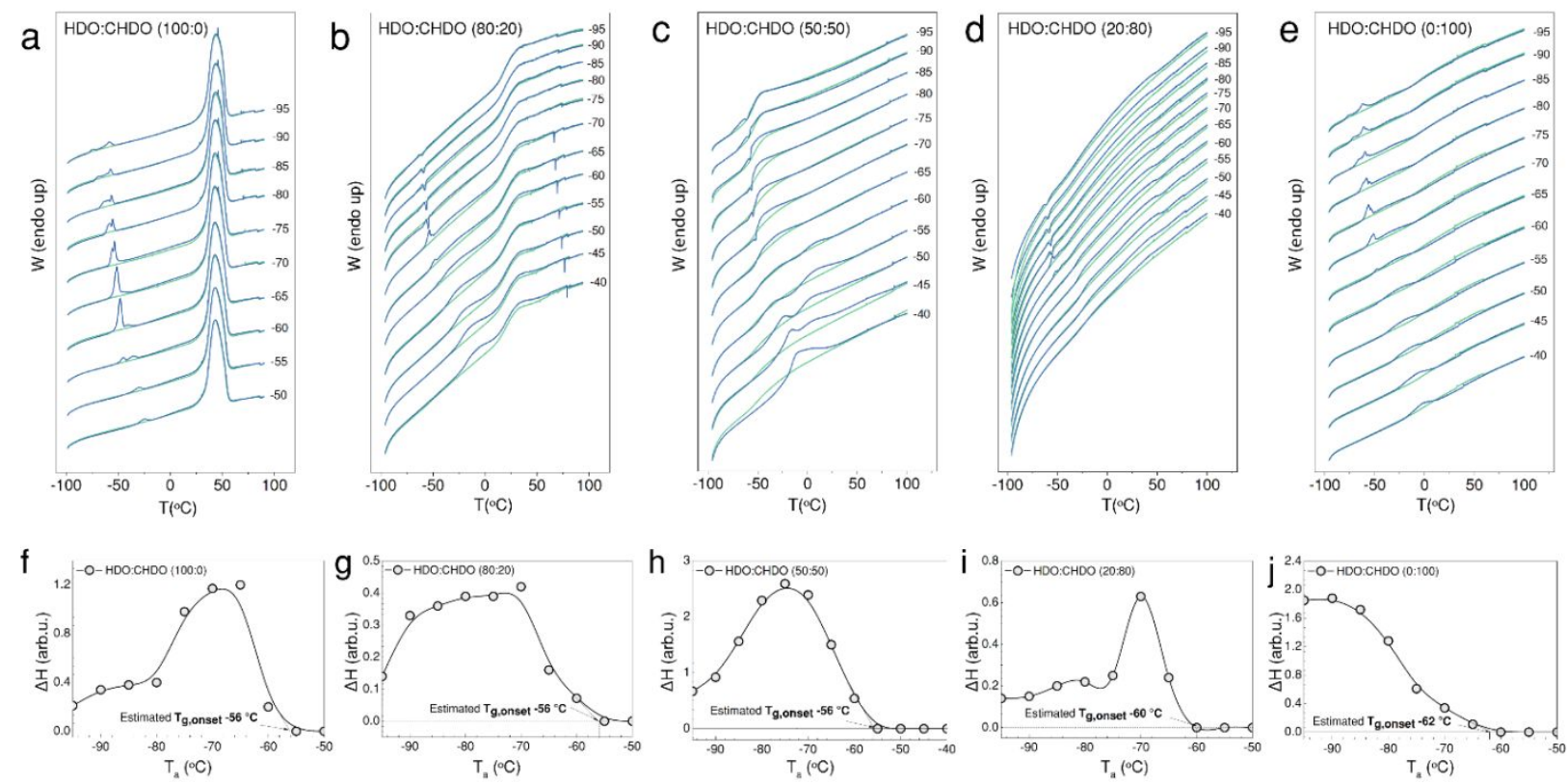

Figure S4. (a-e) Heat flow (W) scans for a) pure HDO, b) HDO:CHDO 80:20, c) HDO:CHDO 50:50, d) HDO:CHDO 20:80 and e) pure CHDO, aged for $10 \mathrm{~min}$ at the indicated temperatures. (f-j) Relaxed enthalpy as a function of ageing temperature, $\mathrm{T}_{a}$, for f) pure HDO, g) HDO:CHDO 80:20, h) HDO: CHDO 50:50, i) HDO:CHDO 20:80 and j) pure CHDO. 


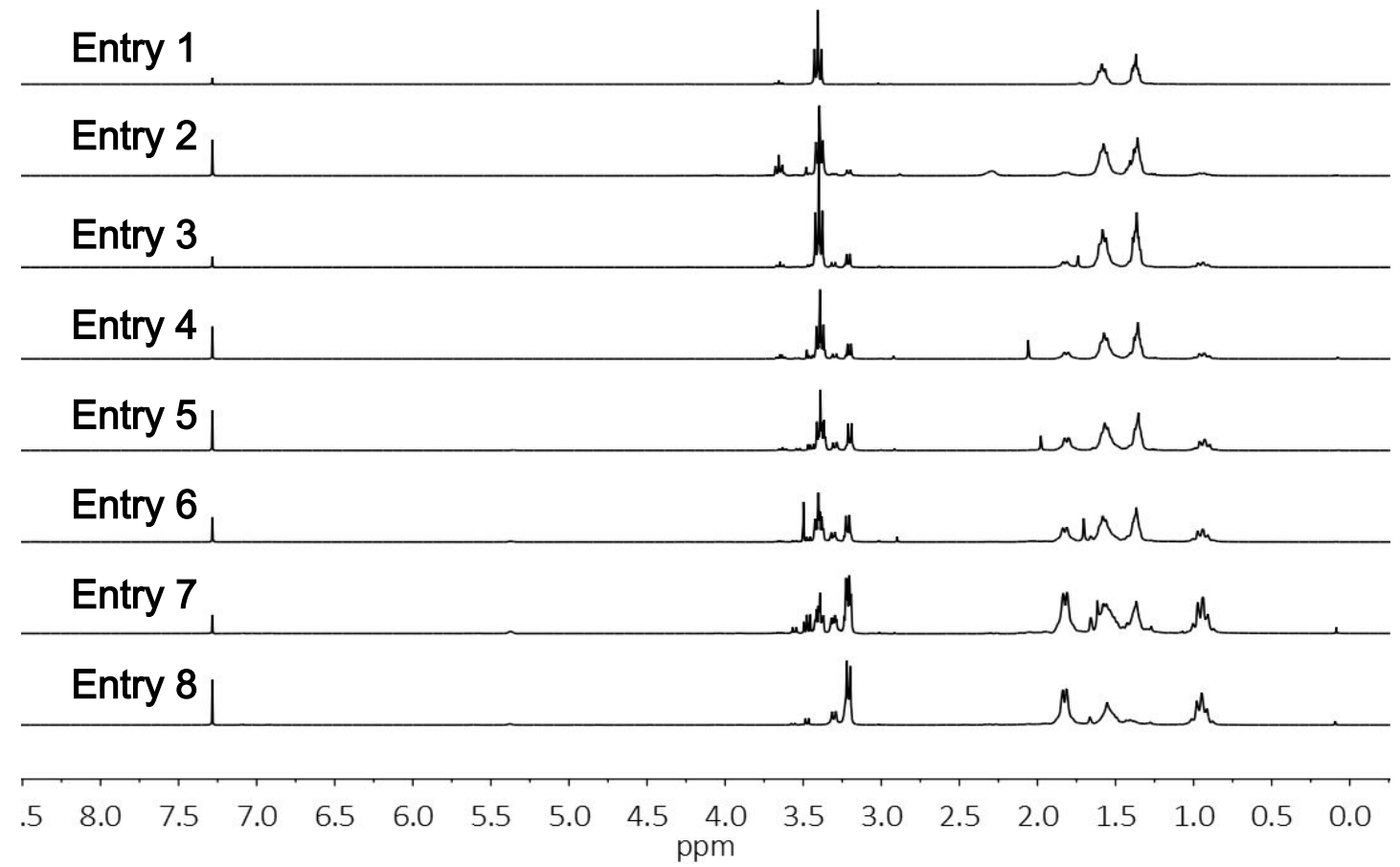

Figure S5. ${ }^{1} \mathrm{H}$ NMR spectroscopy in $\mathrm{d}-\mathrm{CDCl}_{3}$ of the copolymers.

Entry 1

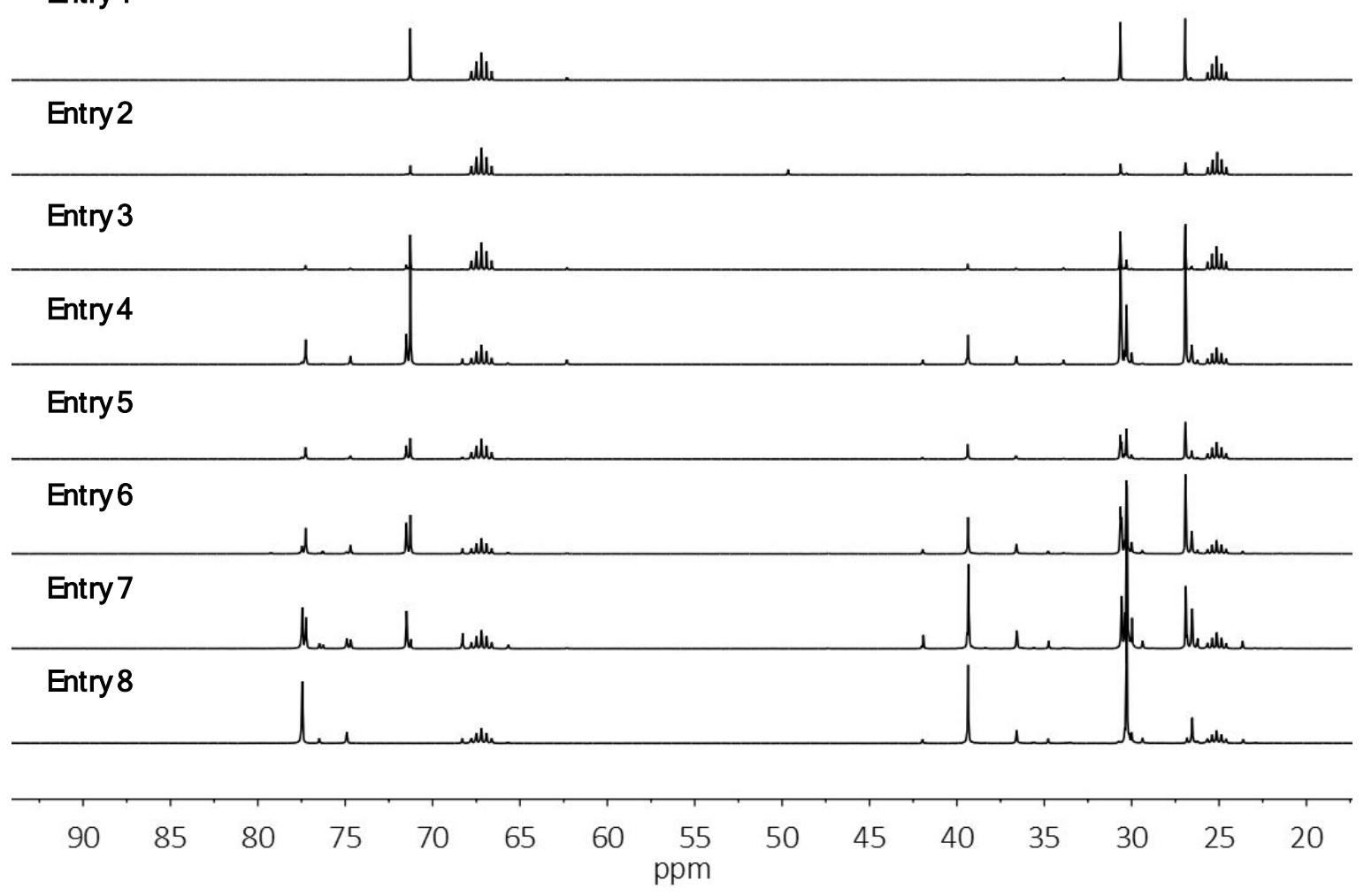

Figure s6. ${ }^{13} \mathrm{C}$ NMR spectroscopy in $\mathrm{THF}$ of the copolyethers. 
Table s1. Chemical compositions and molecular characteristics of the copolyethers.

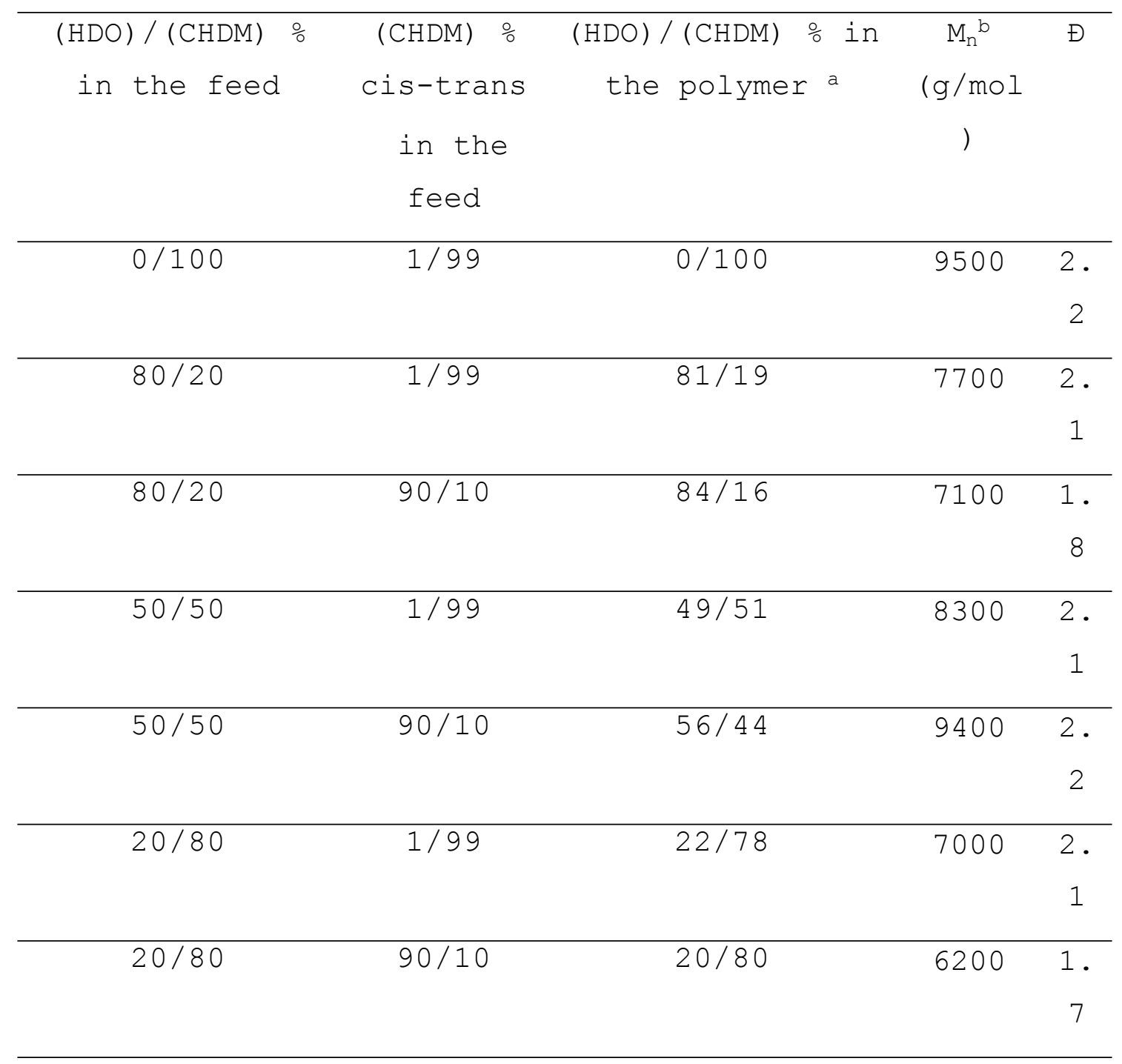

aDetermined by ${ }^{1} \mathrm{H}$ NMR spectroscopy in $\mathrm{CDCl}_{3}$, ${ }^{b}$ Determined by $\mathrm{SEC}$ in $\mathrm{CHCl}_{3},{ }^{C}$ Determined by ${ }^{13} \mathrm{C} \mathrm{NMR}$ spectroscopy in $\mathrm{CDCl}_{3}$ 
HDO/99\%trans-OHDM 80/20

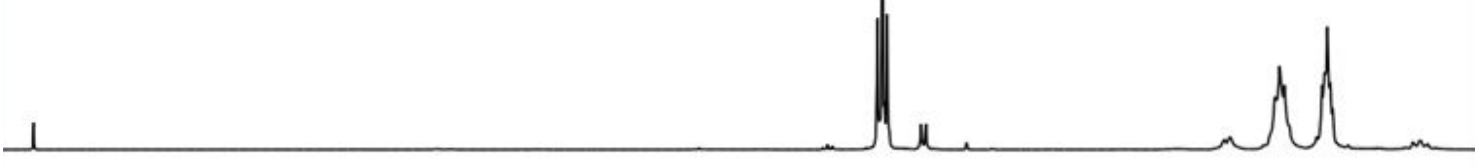

HDO/ 99\% transOHDM 50/50

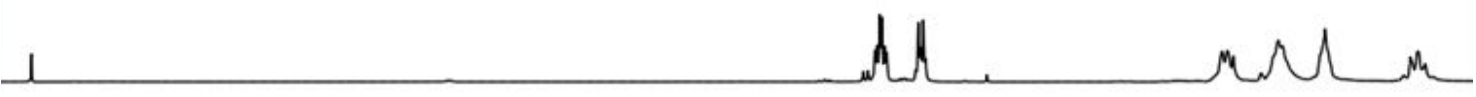

HDO/ 99\% transoHDM 20/80

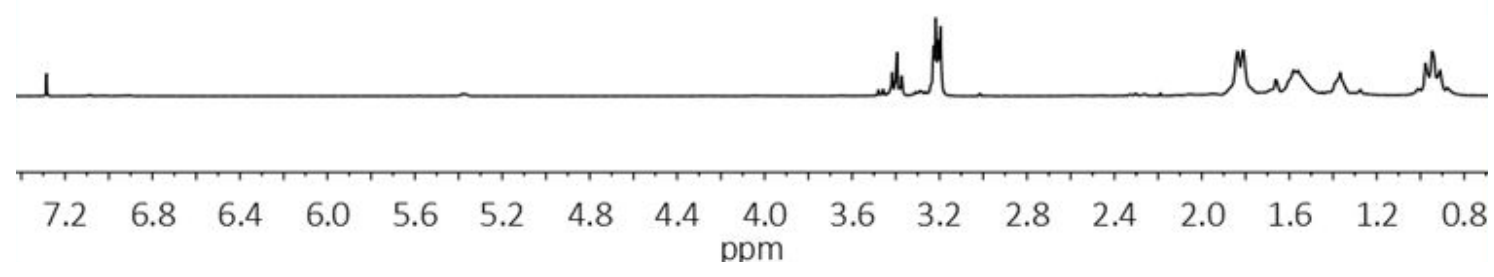

Figure s7. ${ }^{1} \mathrm{H}$ NMR spectroscopy in $\mathrm{d}-\mathrm{CDCl}_{3}$ of the copolymers synthetized using 1-99\% cis/trans-CHDM.

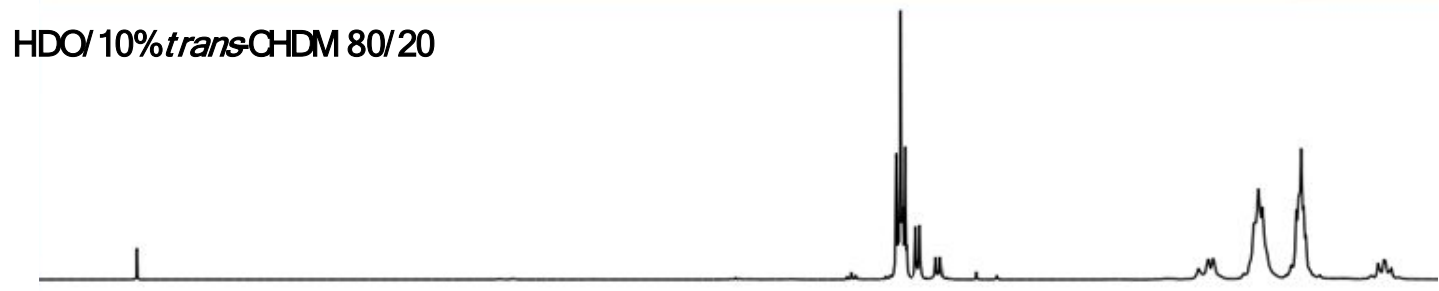

HDO/ 10\%transOHDM 50/50

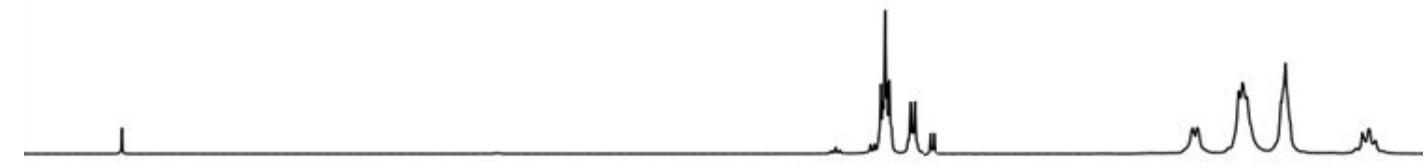

HDO/ 10\% transoHDM 20/80

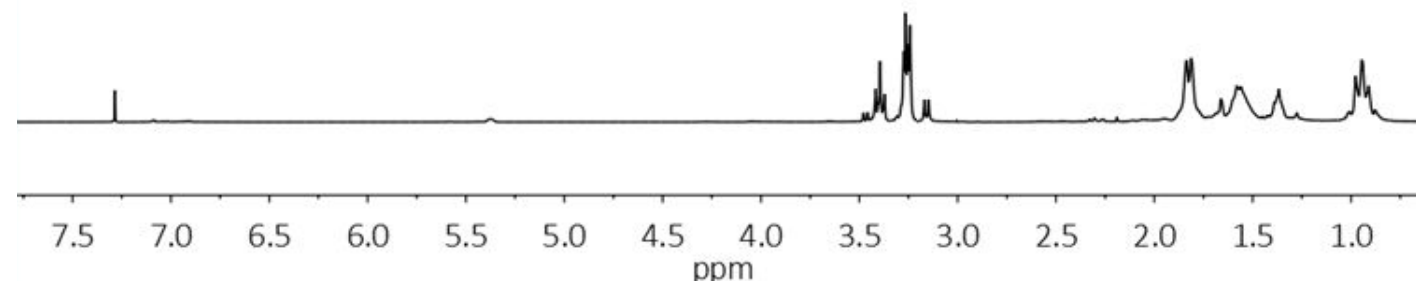

Figure s8. ${ }^{1} \mathrm{H}$ NMR spectroscopy in $\mathrm{d}-\mathrm{CDCl}_{3}$ of the copolymers synthetized using 90-10\% cis/trans-CHDM. 
Table s2. Influence of isomer composition on the thermal properties of the copolyethers.

\begin{tabular}{ccccc}
\hline $\begin{array}{c}\text { (CHDM) } \\
\text { Cis/trans in the } \\
\text { feed }\end{array}$ & $\begin{array}{c}\text { Sample } \\
(\mathrm{HDO} / \mathrm{CHDM})\end{array}$ & $\mathrm{T}_{C}\left({ }^{\circ} \mathrm{C}\right)$ & $\begin{array}{c}\Delta \mathrm{H}_{C} \\
(\mathrm{~J} / \mathrm{g})\end{array}$ & $\mathrm{T}_{m}\left({ }^{\circ} \mathrm{C}\right)$ \\
\hline $1 / 99$ & $0 / 100$ & 25 & -39 & 45.2 \\
\hline $1 / 99$ & $20 / 80$ & 17 & -25 & 29.9 \\
\hline $1 / 99$ & $50 / 50$ & 7.3 & -23 & 18.2 \\
\hline $1 / 99$ & $80 / 20$ & 21 & -38 & 35.4 \\
\hline $90 / 10$ & $20 / 80$ & - & - & - \\
\hline $90 / 10$ & $50 / 50$ & 2.2 & -5 & 7.7 \\
\hline $90 / 10$ & $80 / 20$ & 5.5 & -11 & 12.1 \\
\hline
\end{tabular}

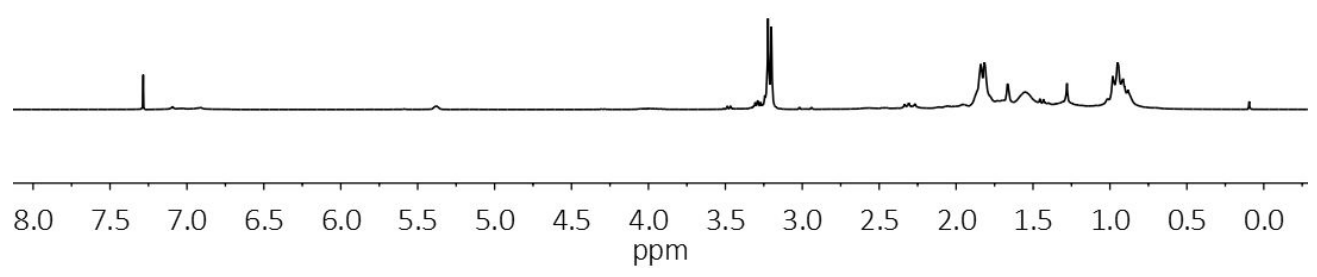

Figure s9. ${ }^{1} \mathrm{H}$ NMR spectroscopy in $\mathrm{d}-\mathrm{CDCl}_{3}$ of the homopolymers synthetized using 1-99\% cis/trans-CHDM. 


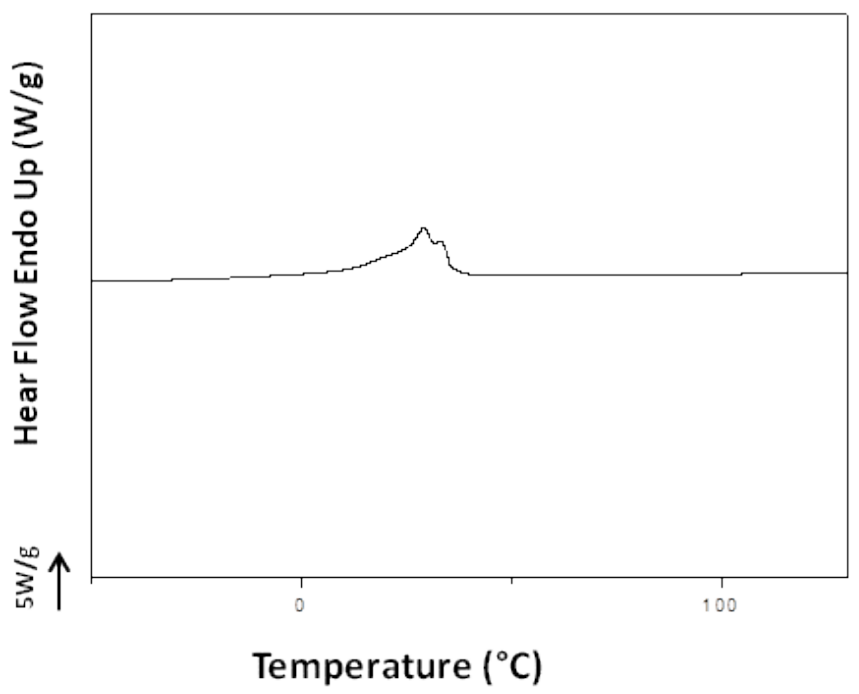

Figure s10. DSC heating and cooling scan of the polyether obtained from 99\% trans-CHDM. 